\title{
FIELD EVALUATION OF SPATIAL REPELLENCY OF METOFLUTHRIN-IMPREGNATED LATTICEWORK PLASTIC STRIPS AGAINST AEDES AEGYPTI (L.) AND ANALYSIS OF ENVIRONMENTAL FACTORS AFFECTING ITS EFFICACY IN MY THO CITY, TIEN GIANG, VIETNAM
}

\author{
HITOSHI KAWADA,* TOMONORI IWASAKI, LUU LE LOAN, TRAN KHANH TIEN, NGUYEN THI NHU MAI, \\ YOSHINORI SHONO, YASUYUKI KATAYAMA, AND MASAHIRO TAKAGI \\ Department of Vector Ecology and Environment, Institute of Tropical Medicine, Nagasaki University, Nagasaki, Japan; Agricultural \\ Chemicals Research Laboratory, Sumitomo Chemical Co. Ltd., Hyogo, Japan; Pasteur Institute, Ho Chi Minh City, Vietnam;
} Tien Giang Preventive Medicine Center, My Tho City, Vietnam

\begin{abstract}
Spatial repellency of metofluthrin-impregnated polyethylene latticework plastic strips against Aedes aegypti mosquitoes was evaluated. Analysis of environmental factors affecting the efficacy of these strips, such as room temperature, humidity, and house structure, was performed in a residential area in My Tho City, Tien Giang Province, Vietnam. Treatment with the strips at the rate of 1 strip per $2.6-5.52 \mathrm{~m}^{2}$ (approximately $600 \mathrm{mg}$ per $2.6-5.52 \mathrm{~m}^{2}$ ) reduced the collection of Ae. aegypti resting inside the houses for at least eight weeks. Multiple regression analysis indicated that both increase in the average room temperature and decrease in the area of openings in the rooms that were treated with the strips positively affected the spatial repellency of metofluthrin.
\end{abstract}

\section{INTRODUCTION}

Metofluthrin, 2,3,5,6-tetrafluoro-4-methoxymethylben$\operatorname{zyl}(E, Z)(1 R, 3 R)$-2,2-dimethyl-3-(prop-1-enyl)cyclopropanecarboxylate $\left(\right.$ SumiOne $\left.{ }^{\circledR}\right)$, is a newly synthesized pyrethroid produced by Sumitomo Chemical Co., Ltd. (Osaka, Japan). Its knockdown and lethal activity against mosquitoes has been demonstrated. ${ }^{1}$ The vapor pressure of metofluthrin $\left(1.87 \times 10^{-3} \mathrm{~Pa}\right.$ at $\left.25^{\circ} \mathrm{C}\right)$ is 2 -fold and 100 -fold greater than those of $d$-allethrin and permethrin, respectively. The high vapor pressure enables metofluthrin to vaporize at normal temperatures without heating, whereas the other conventional pyrethroids require heating for evaporation. The unique characteristics of metofluthrin may lead to the development of new mosquito controlling devices that require no external energy for vaporization, are low-cost devices, and provide long-term efficacy with little maintenance cost. In preliminary studies in which a simple prototype device with metofluthrin-impregnated multilayer paper strips were used, the chemical showed promising spatial repellent effect against mosquitoes in laboratory and field conditions. ${ }^{2,3}$ Mosquitoes were repelled by airborne metofluthrin vapors for four weeks under simulated outdoor conditions. ${ }^{2}$ The field tests also suggested that metofluthrin may be useful for prevention of mosquito bites in shelters without walls (beruga). These shelters are used by people in Lombok Island, Indonesia, for resting, praying, and evening conversations with their neighbors, and are associated with a high risk of malaria transmission. ${ }^{3}$ However, during another preliminary trial in Lombok, the effective duration of the paper strips was shorter than expected. ${ }^{4}$

To achieve a longer effectiveness, we manufactured a cylindrical slow-release plastic formulation that was impregnated with $1,000 \mathrm{mg}$ of metofluthrin. Using this formulation (at the rate of four strips per beruga), we achieved more than 14 weeks of activity under outdoor conditions in Lombok. ${ }^{4}$ Recently, the spatial repellency of this cylindrical plastic for-

* Address correspondence to Hitoshi Kawada, Department of Vector Ecology and Environment, Institute of Tropical Medicine, Nagasaki University, Nagasaki 852-8523, Japan. E-mail: vergiss@nagasakiu.ac.jp mulation was evaluated against mosquitoes in Do Son, Hai Phong City, Vietnam. ${ }^{5}$ The mosquito indices of the dominant species (Culex quinquefasciatus Say and Aedes aegypti [L.]) resting in metofluthrin-treated houses (at the rate of one strip per room) were reduced rapidly immediately after the treatment with metofluthrin strips, and significantly lower values were maintained at least for six weeks. This study confirmed the long-lasting spatial repellent efficacy of metofluthrinimpregnated plastic strips against mosquitoes under indoor conditions. However, the effective duration (six weeks) of repellency of these strips still appeared to be insufficient for the practical use of these devices.

We believe that the long-term effectiveness of metofluthrin-impregnated devices may be achieved by designing devices with different shapes and/or adopting formulations with different optimal composition and densities of the plastic polymer to reduce the release rate of the active ingredient, as well as by increasing the concentration of the active ingredient. Accordingly, as a next step for developing the devices, we manufactured a new latticework plastic strip that was designed to reduce the release rate of metofluthrin to approximately $50 \%$ that of the previous formulation. The present study reports the efficacy of the new prototypes of metofluthrin-impregnated plastic strips against Ae. aegypti in My Tho City, Tien Giang Province, Vietnam. In this study, we also report the statistical analysis of the relationships between spatial repellent efficacy and some environmental factors such as temperature, humidity, and house structures.

\section{MATERALS AND METHODS}

Metofluthrin-impregnated latticework plastic strips. New plastic strips were supplied by Sumitomo Chemical Co. Ltd. The plastic material had a latticework structure $\left(8 \times 11 \mathrm{~cm}^{2}\right.$, $0.46 \mathrm{~cm}$ in thickness, $12.3 \mathrm{~g}$ ) with 240 square holes per strip. The strip was made of polyethylene impregnated with $5 \%$ (w/w) metofluthrin (Figure 1). The new latticework plastic strip was designed to reduce the release rate of metofluthrin to approximately $50 \%$ that of the previous formulation. ${ }^{4,5}$

Location of the field study. The field study was conducted in My Tho City, Tien Giang Province, Vietnam $\left(10^{\circ} 20^{\prime}-\right.$ 


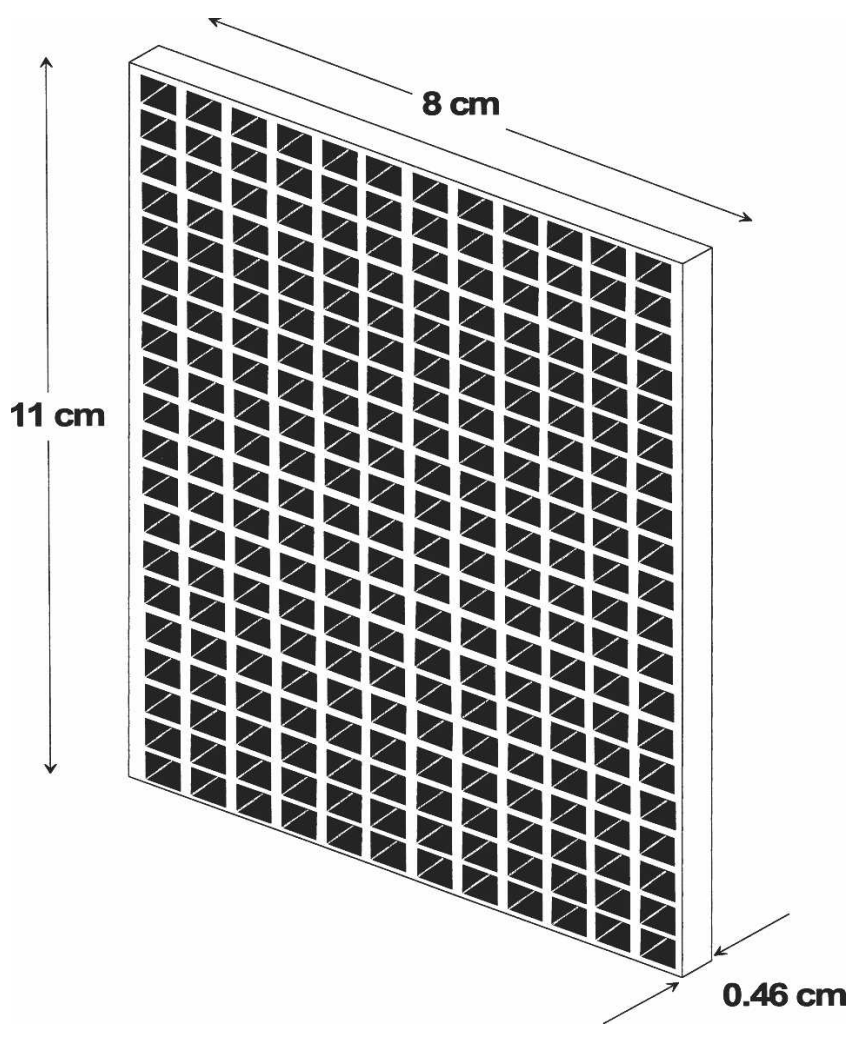

FIGURE 1. Metofluthrin-impregnated polyethylene latticework plastic strip used in the study.

$\left.10^{\circ} 25^{\prime} \mathrm{N}, 106^{\circ} 20^{\prime}-106^{\circ} 25^{\prime} \mathrm{E}\right)$. My Tho City is located in central Tien Giang Province in southern Vietnam and is recognized as one of the commercial cities in the country. It has a total area of $48.3 \mathrm{~km}^{2}$ and a population of 16,500 . This area has a typical tropical climate; the average temperature is constantly high throughout the year and the rainy season lasts from $\mathrm{Au}-$ gust to December. Between January and November 2005, 168 dengue cases, including 1 death, were reported in My Tho City. Volunteers from the study sites were recruited after obtaining informed consent. The protocol for this study was reviewed and approved by the ethical review committee of the National Institute of Health and Epidemiology, Vietnam and Institute of Tropical Medicine, Nagasaki University, Japan, prior to starting the trial.

Strip treatment and mosquito collection. The trial site was divided into two areas; one was designated for untreated controls and the other was designated for treatment. Fifteen houses were randomly selected in both areas. The treatment with metofluthrin-impregnated plastic strips was conducted on June 14, 2005. The strips were directly hung from the ceiling or suspended with a rope inside the rooms at the rate of 1 strip per 2.6-5.52 $\mathrm{m}^{2}$ (Figure 2). A total of 113 strips were used for treating 15 houses. A preliminary survey for mosquito density was conducted for two consecutive weeks prior to the treatment.

Mosquito collection in the houses was conducted one day, one week, and two weeks after treatment. The same procedure was repeated at intervals of 2 weeks until 12 weeks after treatment. Mosquito collection was conducted by a conventional method using mechanical aspirators to catch mosquitoes resting on the walls, under the furniture, and on clothes.

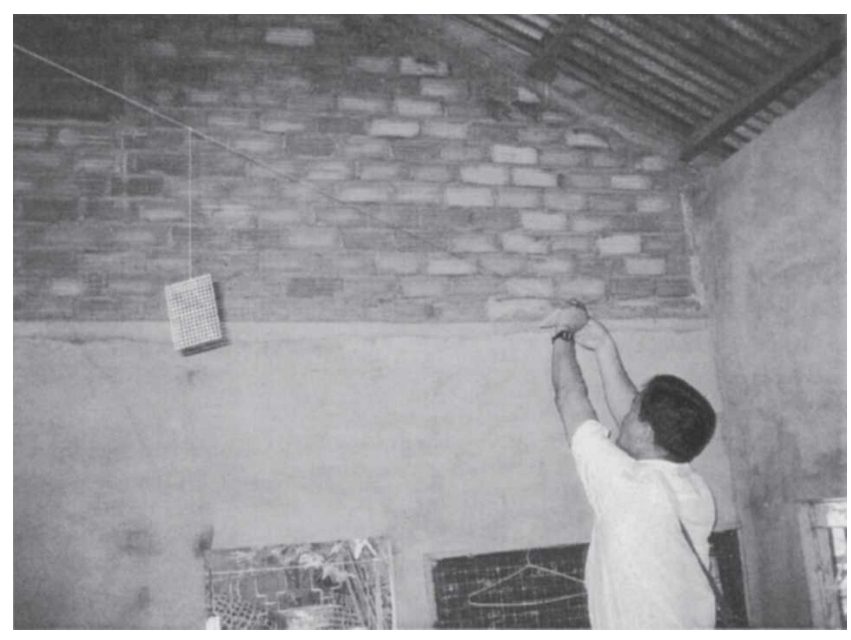

FIGURE 2. Treatment with metofluthrin-impregnated plastic strips in a room, My Tho City, Vietnam.

The mosquitoes were collected between 9:00 AM and 11:00 AM. The total collection time in each house was 20 minutes, 10 minutes by each of the 2 collectors. After the collection, the mosquitoes were identified, the number of mosquitoes per house was recorded, and the mosquito density index (female mosquitoes per house) was calculated. The age of the female mosquitoes (parous or nulliparous) was also determined anatomically according to the method of Detinova. ${ }^{6}$

Measurement of environmental factors. Seven metofluthrin-treated houses (house nos. 2, 4, 5, 7, 8, 9, and 10) were randomly selected for the analysis. Environmental factors such as room temperature, humidity, floor area, room volume, window area, door area, and areas of other openings (ventilators) were measured. Throughout the trial, the room temperature and humidity were recorded on an hourly basis using a data logger $\left(\mathrm{HOBO}^{\circledR}\right.$; Onset Computer Corp., Bourne, MA).

Measurement of metofluthrin concentration in air. Two metofluthrin-treated houses (house nos. 5 and 7) were selected for measurement of metofluthrin concentration in air. On days 1 and 2 after the treatment with the devices, the air from 2 rooms in each house (500 mL per room) was sucked at the rate of $5 \mathrm{~mL} / \mathrm{minute}$ through a sampling glass column packed with polyurethane sponge; the end of the glass column was connected to an air sampler (GilAir-5; Kanomax Inc., Andover, NJ) through a silicon tube. The sampling position was at a height of $120 \mathrm{~cm}$ from the center of the floor. Sampling was conducted between 8:00 AM and 11:30 AM. After sampling, the glass column was eluted with hexane and the eluant was concentrated; it was then subjected to gas chromatography analysis using Agilent Model 6890N gas chromatograph and Agilent Chemstation (Agilent Industries Co., Palo Alto, CA) with an ECD detector and column (HP-50 + $50 \%$ phenyl methyl siloxane, internal diameter $=250 \mu \mathrm{m}$, film thickness $=0.25 \mu \mathrm{m}$, length $=30 \mathrm{~m}$ ). The column and injection temperatures were $195^{\circ} \mathrm{C}$ and $250^{\circ} \mathrm{C}$, respectively.

Data analysis. The density index was calculated as the mean number of resting female Ae. aegypti collected in a house. The individual numbers of mosquitoes per house per day in the treated and untreated houses were compared using repeated measures analysis of variance (ANOVA). Stepwise 


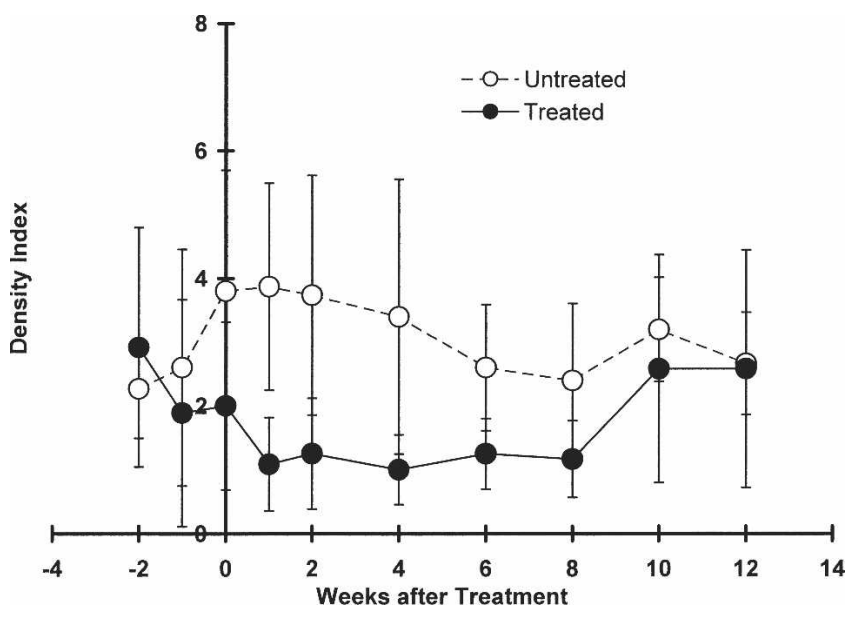

FIGURE 3. Changes in the mosquito density index (female per house per day) of Aedes aegypti collected in metofluthrin-treated and untreated houses. Error bars indicate $95 \%$ confidence limits.

multiple regression analysis was performed to analyze the effects of environmental factors on the spatial repellent efficacy of metofluthrin-impregnated strips.

\section{RESULTS}

Residual spatial repellency of metofluthrin-impregnated plastic latticework strips against Ae. aegypti. The dominant species found at the trial sites was $A$ e. aegypti, followed by $C x$. quinquefasciatus. A small number of $C x$. pseudovishnui Colless were also collected. Changes in the number of female $A e$. aegypti collected from metofluthrin-treated and untreated houses are shown in Figure 3. The mosquito indices of both treated and untreated sites were 2.92 and 2.27, respectively, at 2 weeks prior to the treatment and 1.89 and 2.60, respectively, at 1 week prior to treatment. After the treatment with metofluthrin-impregnated strips, the mosquito indices of the treated houses remained significantly lower than those of the untreated houses $(\mathrm{F}=11.68$, degrees of freedom $=224, P<$ 0.001 , by repeated measures ANOVA). The mosquito index of metofluthrin-treated sites increased to the pretreatment (2.58) level at 10 weeks after treatment. Thus, the effective duration of repellency of metofluthrin against Ae. aegypti was found to be less than 10 weeks. Changes in the parity rate of female Ae. aegypti collected from metofluthrin-treated and untreated houses are shown in Table 1 . The parity rates that were observed at both sites showed a relatively high value $(>50 \%)$; no significant differences were observed between metofluthrin-treated and untreated sites during the 12 weeks, except for that at 1 week after the treatment.

Analysis of environmental factors affecting the spatial repellent efficacy of metofluthrin-impregnated latticework strips. The environmental factors measured in this study are listed in Table 2. The average temperature and humidity were calculated on an hourly basis from June 20 to September 4, 2005. In houses with several rooms for treatment, structural factors such as the floor area, volume, and area of openings were calculated as a total of the factors. The corrected open area for each house was calculated as the sum of the window area, half the door area (since doors were normally closed at night), ventilator area, and area of any other opening. Hourly changes in temperature and humidity in two typical houses, one with a large open area (house no. 5; corrected open area $=9.7 \mathrm{~m}^{2}$, floor area $=30.8 \mathrm{~m}^{2}$ ), and the other with a small open area (house no. 7 ; corrected open area $=4.4 \mathrm{~m}^{2}$, floor area $\left.=39.0 \mathrm{~m}^{2}\right)$, suggest that the temperature was lower $(\mathrm{t}=$ 25.2, $P<0.01)$ and humidity was higher $(\mathrm{t}=22.3, P<0.01)$ in houses with a large open area than in those with a small open area (Figure 4). The mean metofluthrin concentrations in air at 1 and 2 days after the treatment in the two houses were $0.16 \mu \mathrm{g} / \mathrm{m}^{3}$ for house no. 5 and $0.43 \mu \mathrm{g} / \mathrm{m}^{3}$ for house no. 7 (Table 2). The aerial concentration was believed to be in the highly safety level because the no observed adverse effect level of metofluthrin for male and female rats was reported to be $98.7 \mathrm{mg} / \mathrm{m}^{3}{ }^{7}$ Results in Table 2 indicate that the spatial repellent efficacy, metofluthrin concentration in air, average temperature, and average humidity were correlated with the house structure. The stepwise multiple regression analysis with $A e$. aegypti density as a dependent variable identified both the average temperature and the corrected area of openings as the significant variables. The opening rate that was calculated as the corrected area of openings per volume also appeared to affect the efficacy; however, no significant difference was observed with regard to the opening rate between metofluthrin-treated and untreated houses (Table 3 ).

\section{DISCUSSION}

Multiple regression analysis of environmental factors indicated that both an increase in average room temperature and a decrease in area of openings in rooms that were treated with metofluthrin-impregnated strips positively affected its spatial repellency. The increase in temperature might positively enhance the evaporation rate, and the decrease in area of openings might retain the active ingredient inside the rooms,

TABLE 1

Changes in parity rate of Aedes aegypti collected in metofluthrin-treated and untreated houses

\begin{tabular}{|c|c|c|c|c|c|c|c|c|}
\hline \multirow[b]{2}{*}{ Test site } & & \multicolumn{7}{|c|}{ Weeks after treatment } \\
\hline & & 1 & 2 & 4 & 6 & 8 & 10 & 12 \\
\hline \multirow[t]{3}{*}{ Metofluthrin treated } & No. of mosquitoes examined & 19 & 29 & 15 & 20 & 17 & 51 & 54 \\
\hline & No. of parous mosquitoes & 10 & 17 & 9 & 14 & 12 & 27 & 38 \\
\hline & Parity rate $(\%)$ & $52.6 *$ & 58.6 & 60.0 & 70.0 & 70.6 & 52.9 & 70.4 \\
\hline \multirow[t]{3}{*}{ Untreated } & No. of mosquitoes examined & 58 & 56 & 51 & 39 & 34 & 48 & 40 \\
\hline & No. of parous mosquitoes & 46 & 33 & 28 & 28 & 23 & 35 & 25 \\
\hline & Parity rate (\%) & 79.3 & 58.9 & 54.9 & 71.8 & 67.6 & 72.9 & 62.5 \\
\hline
\end{tabular}

* Significant difference between treated and untreated sites $(P<0.05$, by chi-square test for independence) 
TABLE 2

Variables included in the multiple regression analysis of environmental factors affecting the efficacy and aerial concentration of metofluthrin

\begin{tabular}{|c|c|c|c|c|c|c|c|}
\hline \multirow[b]{2}{*}{ Variables } & \multicolumn{7}{|c|}{ House no. } \\
\hline & 2 & 4 & 5 & 7 & 8 & 9 & 10 \\
\hline Average temperature $\left({ }^{\circ} \mathrm{C}\right.$; June $20-$ September 4,2005$)$ & 28.96 & 28.56 & 28.09 & 30.05 & 30.41 & 28.91 & 28.73 \\
\hline Average humidity (\% RH, June 20-September 4, 2005) & 70.55 & 72.85 & 77.53 & 68.79 & 68.04 & 72.09 & 60.87 \\
\hline Floor area $\left(\mathrm{m}^{2}\right)$ & 23.25 & 47.5 & 30.8 & 39.04 & 39.04 & 28.56 & 16.56 \\
\hline Room volume $\left(\mathrm{m}^{3}\right)$ & 55.8 & 166.32 & 132.44 & 191.29 & 191.29 & 119.95 & 48.02 \\
\hline Corrected area of openings $\left(\mathrm{m}^{2}\right) *$ & 2.38 & 3.16 & 9.7 & 4.445 & 4.445 & 16.64 & 5.6 \\
\hline Opening rate (corrected area of openings/floor area) & 10.24 & 6.65 & 31.49 & 11.39 & 11.39 & 58.26 & 33.82 \\
\hline Opening rate (corrected area of openings/volume) & 0.04 & 0.02 & 0.07 & 0.02 & 0.02 & 0.14 & 0.12 \\
\hline Floor area/strip $\left(\mathrm{m}^{2}\right)$ & 3.32 & 4.75 & 3.08 & 2.79 & 2.79 & 2.60 & 5.52 \\
\hline Volume/strip $\left(\mathrm{m}^{3}\right)$ & 7.97 & 16.63 & 13.24 & 13.66 & 13.66 & 10.90 & 16.01 \\
\hline Efficacy (no. of Ae. aegypti collected) $\dagger$ & 9 & 12 & 23 & 6 & 7 & 31 & 18 \\
\hline Aerial concentration of metofluthrin $\left(\mu \mathrm{g} / \mathrm{m}^{3}\right) \ddagger \S$ & - & - & $0.16(0.06)$ & $0.43(0.11)$ & - & - & - \\
\hline
\end{tabular}

$*$ Corrected area of openings $=$ windows area + Door area $\times 1 / 2+$ ventilator area + other opening area

. Corrected area of openings $=$ windows area + Door area $\times$

Average of the concentration measured 1 day and 2 days after treatment of devices.

$\$$ Values in parentheses are standard deviations.

thereby resulting in an increase in the metofluthrin concentration in air. Moreover, a large area of openings might negatively affect the room temperature.

Studies have reported on the relationship between the structure of a human residence and mosquito invasion. ${ }^{8-11}$ Snow $^{8}$ reported that invasion by endophilic mosquito species such as Anopheles gambiae Giles sensu lato, An. melas Theobald, and Mansonia spp. into the experimental huts in The Gambia was slightly affected by increasing the wall height. Lindsay and others ${ }^{10}$ reported that house entry by $A n$.
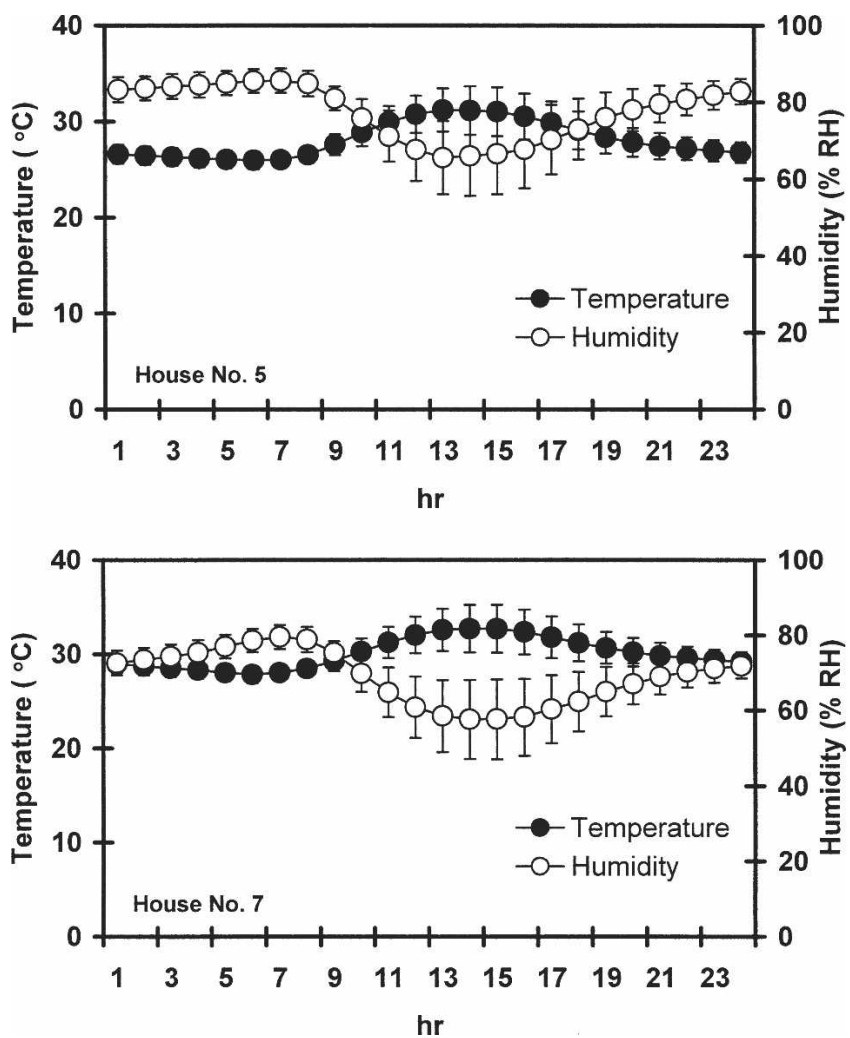

FIGURE 4. Hourly changes in temperature and relative humidity (RH) in two typical houses that had a large open area (house 5) and a small open area (house 7), respectively. Error bars indicate 95\% confidence limits. gambiae was reduced by $37 \%$ after closing the eaves. A similar significant contribution of open eaves to the increase in mosquito invasion was also reported by Pålsson and others. ${ }^{11}$ Therefore, open eaves in the typical rural African houses are believed to be one of the most important entrances for night time invasion by endophilic and nocturnal An. gambiae. However, the site of entry for the diurnal Ae. aegypti appears to be different from that for An. gambiae because the maximum house entry by Ae. aegypti is believed to occur during daytime when most of doors and windows are kept open. Therefore, area of openings in the houses included in this study is believed to have little effect on the mosquito entry into the houses; however, it mainly affects the metofluthrin concentration in air.

In this study, we were able to confirm the long-lasting spatial repellent efficacy of metofluthrin-impregnated latticework plastic strips against Ae. aegypti. The effective duration of repellency of this new device appears to be longer than that of the previous cylindrical strips, ${ }^{5}$ although the trial sites and dosages of these two devices were different. The new latticework plastic strip was designed to reduce the release rate of metofluthrin to approximately $50 \%$ that of the previous device, whereas the dosage of the active ingredient used in the new device (120-200 mg/m $\mathrm{m}^{2}$ ) was calculated to be approximately 1-2 times higher than that used in the previous device. However, the effective duration of repellency was still considered to be insufficient for the practical application of these devices. Six months or more effective duration is desirable if we consider the convenience for the re-treatment. Further improvements in the manufacturing of plastic strips, such as designing new shapes and/or adopting the optimum compo-

TABLE 3

Multiple regression coefficients of number of mosquitoes collected in metofluthrin-treated houses

\begin{tabular}{lcccc}
\hline & $\begin{array}{c}\text { Regression } \\
\text { coefficient }\end{array}$ & SE & $\begin{array}{c}\text { Standardized } \\
\text { partial } \\
\text { coefficient }\end{array}$ & $P$ \\
\hline $\begin{array}{l}\text { Average temperature } \\
\begin{array}{l}\text { Corrected area } \\
\text { of openings }\end{array}\end{array}$ & -3.82 & 0.648 & -0.341 & 0.0097 \\
$\begin{array}{l}\text { Corrected area } \\
\text { of openings/volume }\end{array}$ & 1.18 & 0.155 & 0.637 & 0.0047 \\
\hline
\end{tabular}


sition and density of the plastic polymer to optimize the release rate of the active ingredient, will hopefully enable the formulation of an optimum recipe that would result in a longer effective duration.

The high parity rate and lack of significant difference in mosquito ages between metofluthrin-treated and untreated houses indicate that metofluthrin did not have a great impact on mosquito survival. Generally, mosquito age composition is believed to deviate toward young age from selective pressure of effective insecticide treatment because insecticidal susceptibility of mosquitoes show a negative correlation with their ages. ${ }^{12-15}$ Doannio and others ${ }^{13}$ reported from Côte d'Ivoire that the parity rate of $A n$. gambiae sensu lato was reduced from 40.6 to lower levels (20.1 after 12 weeks and 26.2 after 24 weeks, respectively) after insecticide-treated nets were introduced, thereby demonstrating the effect of these nets on the survival of mosquitoes. Kawada and others ${ }^{2-5}$ reported that mosquitoes were repelled by airborne metofluthrin vapors because of the two main modes of pyrethroid action, knockdown activity and biting inhibition or disruption of orientation toward the host. The latter mode may be categorized as a sub-lethal effect that results from neural excitement, which appears to occur at an earlier stage of pyrethroid toxicity. ${ }^{16-18}$ Therefore, the reduction in the resting mosquitoes in metofluthrin-treated houses with a low impact on the mosquito survival is considered to be caused mainly by two modes of action of metofluthrin mentioned above. Such a low impact of metofluthrin on mosquito survival, which is a common observation in the case of other household pyrethroids, may have an advantage by minimizing development of insecticide resistance.

Received April 24, 2006. Accepted for publication July 28, 2006.

Acknowledgments: We express our deep gratitude to K. Watanabe (Sumika LifeTech Co., Ltd., Osaka, Japan) for providing the plastic samples. We also thank H. T. T. Tran (Pasteur Institute, Ho Chi Minh City, Vietnam) for assistance with the study.

Financial support: This study was supported by the Core University Program sponsored by the Japan Society for the Promotion of Science.

Authors' addresses: Hitoshi Kawada and Masahiro Takagi, Department of Vector Ecology and Environment, Institute of Tropical Medicine, Nagasaki University, Nagasaki 852-8523, Japan. Tomonori Iwasaki, Yoshinori Shono, and Yasuyuki Katayama, Agricultural Chemicals Research Laboratory, Sumitomo Chemical Co., Ltd., Hyogo 665-8555, Japan. Luu Le Loan and Tran Khanh Tien, Pasteur Institute, Ho Chi Minh City, Vietnam. Nguyen Thi Nhu Mai, Tien Giang Preventive Medicine Center, My Tho City, Vietnam.

\section{REFERENCES}

1. Ujihara K, Mori T, Iwasaki T, Sugano M, Shono Y, Matsuo N, 2004. Metofluthrin: A potent new synthetic pyrethroid with high vapor activity against mosquitoes. Biosci Biotechnol Biochem 68: 170-174.

2. Kawada H, Maekawa Y, Tsuda Y, Takagi M, 2004. Laboratory and field evaluation of spatial repellency with metofluthrinimpregnated paper strip against mosquitoes in Lombok Island, Indonesia. J Am Mosq Control Assoc 20: 292-298.

3. Kawada H, Maekawa Y, Tsuda Y, Takagi M, 2004. Trial of spatial repellency of metofluthrin-impregnated paper strip against Anopheles and Culex in shelters without walls in Lombok, Indonesia. J Am Mosq Control Assoc 20: 434-437.

4. Kawada H, Maekawa Y, Takagi M, 2005. Field trial of the spatial repellency of metofluthrin-impregnated plastic strip against mosquitoes in shelters without walls (Beruga) in Lombok, Indonesia. $J$ Vector Ecol 30: 181-185.

5. Kawada H, Yen Ng T, Hoa Ng T, Sang Tr M, Dan Ng V, Takagi M, 2005. Field evaluation of spatial repellency with metofluthrin impregnated resin strips against mosquitoes in Hai Phong city, Vietnam. Am J Trop Med Hyg 73: 350-353.

6. Detinova TS, 1962. Age Grouping Methods in Diptera of Medical Importance, with Special Reference to Some Vectors of Malaria. Monograph Series 47. Geneva: World Health Organization.

7. Matsuo N, Ujihara K, Shono Y, Iwasaki T, Sugano M, Yoshiyama T, Uwagawa S, 2005. Discovery and development of a novel pyrethroid insecticide "metofluthrin (Sumione ${ }^{\circledR}$, Eminence $\left.{ }^{\circledR}\right)$ ". Sumitomokagaku 2: 4-16.

8. Snow WF, 1987. Studies of house-entering habits of mosquitoes in The Gambia, West Africa: experiments with prefabricated huts with varied wall apertures. Med Vet Entomol 1: 9-21.

9. Charlwood JD, Pinto J, Ferrara PR, Sousa CA, Ferreira C, Gil V, do Rosario VE, 2003. Raised houses reduce mosquito bites. Malar J 2: 45.

10. Lindsay SW, Jawara M, Paine K, Pinder M, Walraven GEL, Emerson PM, 2003. Changes in house design reduce exposure to malaria mosquitoes. Trop Med Int Health 8: 512-517.

11. Pålsson K, Jaenson TGT, Dias F, Laugen AT, Björkman A, 2004. Endophilic Anopheles mosquitoes in Guinea Bissau, west Africa, in relation to human housing conditions. J Med Entomol 41: 746-752.

12. Lines JD, Nassor NS, 1991. DDT resistance in Anopheles gambiae declines with mosquito age. Med Vet Entomol 5: 261-265.

13. Doannio JMC, Dossou-Yovo J, Diarrassouba S, 1999. Efficasité des moustiquaires pré-imprégnées de permethrine Olyset net en zone de résistance des vecteus aux pyrethrinoides I-evaluation entomologique. Med Trop (Mars) 59: 349-354.

14. Hodjati MH, Curtis CF, 1999. Evaluation of the effect of mosquito age and prior exposure to insecticide on pyrethroid tolerance in Anopheles mosquitoes (Diptera: Culicidae). Bull Entomol Res 89: 329-337.

15. Takken W, 2002. Do insecticide-treated bednets have an effect on malaria vectors? Trop Med Int Health 7: 1022-1030.

16. MacIver DR, 1964. Mosquito coils Part II. Studies on the action of mosquito coil smoke on mosquitoes. Pyrethrum Post 7: 7-14.

17. Winney R, 1975. Pyrethrins and pyrethroids in coils-a review. Pyrethrum Post 13: 17-22.

18. Birley MH, Mutero CM, Turner IF, Chadwick PR, 1987. The effectiveness of mosquito coils containing esbiothrin under laboratory and field conditions. Ann Trop Med Parasitol 81: 163-171. 